\title{
Managing team learning in a Spanish commercial bank
}

\author{
Erik Døving
}

\author{
Irene Martín-Rubio
}

\begin{abstract}
Purpose - The purpose of this paper is to analyze how team management affects team-learning activities.

Design/methodology/approach - The authors empirically study 68 teams as they operate in the natural business context of a major Spanish bank. Quantitative research utilizing multiple regression analyses is used to test hypotheses.

Findings - The leadership behaviour (consideration, initiation of structure) displayed by the team leader plays a key role in facilitating team learning. Team leader behaviour characterised by consideration and in particular by initiation of structure are both positively related to team-learning activities. Cross-training of team members also contributes to team-learning behaviour.

Research limitations/implications - A specific setting may limit the generalizability of findings. Further research may accordingly investigate to what extent these results can be generalized to other settings or other aspects of team learning.

Practical implications - The leadership style adopted by the team leader, as well as cross-training of members, affect team-learning activities. These results link leadership theory to collective learning in teams and organizations, and suggest ways leaders can contribute to improved learning.

Originality/value - The study provides new insight into how management of teams facilitates team-learning activities. While consideration is somewhat related to team learning, initiation of structure as well as cross-training appear as key variables.
\end{abstract}

\section{Introduction}

Team learning emerges as an important building block for learning by complex organizations (Bucic et al., 2010; Edmondson, 1999, 2002). Learning by teams is indeed distinct from a mere aggregation of individual learning suggesting that there is a component of learning that should be attributed to the team itself (Argote, 1993; Chan, 2003). The quality and extent of team learning may however vary across teams facing similar tasks within the same company or industry (Edmondson, 2002). These observations call for greater attention to what leaders can do to promote team learning (Bucic et al., 2010).

The aim of this paper is to extend this line of research by investigating to what degree team management affect actual team learning processes. Because managers are 
likely to have a particularly important role within the group of direct subordinates, our point of departure is that the team leader's behaviour may facilitate the team learning process (Bucic et al., 2010; Edmondson, 2003b; Edmondson et al., 2007; Sarin and McDermott, 2003; Srivastava et al, 2006). For instance, Sarin and McDermott (2003) found that a leadership style involving initiation of structure was positively related to team learning whereas consideration was not. Consideration is a type of behaviour where the leader is concerned about team members' welfare and voices appreciation and support; this in turn facilitates team learning process in terms of knowledge sharing and joint reflection. By initiating structure, on the other hand, the manager defines roles and sets goals; this helps to focus team members' attention and energy on sharing useful information. We investigate to what degree the classical dimensions of consideration and initiation of structure facilitates team learning. In conjunction with team leader behaviour we also explore how cross-training (ability to do different jobs or tasks) facilitates collective learning. While some of these relationships have been explored by previous research, comprehensive sets of variables are rarely measured such that the effects of antecedents can be contrasted (Edmondson et al., 2007).

We empirically study branch office teams as they operate in the natural business context of a major Spanish bank. This provides a setting that is relatively homogenous with regard to tasks, customers and the overall corporate environment, such that team characteristics of interest are sharply focused as implied by Edmondson's (2002) findings. Because these team characteristics are largely at the discretion of team managers, they can differ across units or teams of the same organization. Taken together, this warrants a quantitative analysis relating leadership and cross-training to extent of team learning behaviour. In the context of this research a work team is a collection of employees formally defined as an organizational unity and we specifically analyze each branch office as one team. Teams can then be somewhat larger than what is often understood by the term "group". Moreover, the recent review of the research by Edmondson et al. (2007) identified three dominant approaches to team learning: focus on process, focus on intermediate outcomes in terms of task mastery and focus on ultimate outcomes in terms of performance improvements. In line with the first approach we analyze team learning in terms of an on-going process of knowledge sharing, joint reflection and feedback among members of the team (Edmondson, 1999; Wilson et al., 2007). This emphasis on collective learning activities distinguishes team learning from learning by individual employees.

In this paper we first discuss the notion of team learning in relation to learning by the organization as whole. We further discuss leadership and cross-training, and how these can be expected to foster or facilitate team learning. The following section describes how we gathered questionnaire data from 68 branch offices of a single commercial bank. Finally, we analyze these data and discuss the results.

\section{Teams and team learning}

Research on organizational learning has a legacy spanning more than 30 years. Early research on learning in or by organizations observed learning in terms of increases in productivity with time or cumulative output (Yelle, 1979). The intermediate learning processes were however largely assumed and rarely measured. Although it may seem obvious that individual learning at some point must be involved in organizational 
learning, the conceptual and empirical relation between individual and collective learning still remains one of the major challenges in the field (Døving, 1996; Kira and Frieling, 2007; Lähteenmäki et al., 2001; Wilson et al., 2007). In this regard, Chan (2003) found that in a hospital setting individual learning was not related to organizational learning, while individual learning was related to team learning, and team learning was related to organizational learning. This finding suggests that teams are not only distinct units of learning but also relevant intermediate levels. This is crucial because the effects of team learning on overall organizational performance may only partially be mediated by team performance (Crossan et al., 1999). Findings like these support the basic assumption that organizational learning or team learning is more than the aggregate of individual learning, that there is a true system component involved (Argote, 1993; Argote et al., 1995).

Previously, little empirical research connected the extensive knowledge on groups to this expanding field of organizational learning. At the same time the use of work teams has received increased attention. Empirical evidence indicates that the use of work teams in manufacturing has a positive effect on firm performance (Ichniowski et al., 1997); improved learning may be one important mechanism accounting for this effect. Research on team learning has however gained momentum, particularly following Edmondson's (1999) article. While the field is still developing it remains fragmented because both the empirical measures and the very definitions of team learning vary considerably across studies. This shortage of consensus makes it difficult to accumulate empirical evidence (Edmondson et al., 2007; Wilson et al., 2007).

We study a work team in terms of a collection of individuals who are seen by others as a social entity. These individuals are interdependent because of the tasks they perform, the team itself is embedded in a larger organization, and the team perform tasks that affect customers. This implies that teams can be somewhat larger than what is often understood by the term "group". Differences between the two are however a matter of degree rather than fundamental divergences. We study work teams where membership is stable, well-defined and typically, but not necessarily, full-time, but we do not impose any further assumptions about the characteristics of teams.

In the context of team learning, levels of analysis can be confused if individual learning within a group context and learning at the level of the team itself are not distinguished (Wilson et al., 2007). While individual learning is an important component of team learning, individual learning becomes collective only when integrated in the shared understanding and practices of team members (Kira and Frieling, 2007). Even if an individual's learning within the team contributes to aggregate team performance it remains individual learning unless the learning process as such takes place at the team level.

Rather than measuring possible outcomes of learning, such as team performance, we focus instead on the actual learning processes occurring in the team. Focus on the team learning activities corresponds to Edmondson's (1999, p. 353) notion of team learning as an on-going process of reflection and action, including asking questions, seeking feedback, reflecting on results and errors. Such flow of information and knowledge sharing among members allows the team to produce and hold knowledge collectively (Brown and Duguid, 1998; Wilson et al., 2007). In this way, collective learning occurs in close relation to and can become an integral part of everyday work 
in the team (Brown and Duguid, 1991). Our focus on team learning in terms of an on-going process in the workplace also means that learning basically occurs in the same context as knowledge and information is applied (Lave and Wenger, 1991). Sharing experience and knowledge in relation to on-going work can also help team members putting abstract knowledge to effective use in practice. Moreover, managers have a role supporting or encouraging such behaviour in teams (Roberts, 2006). A focus on the process of team learning means that we investigate to what degree behaviour such as information sharing and joint reflection is indeed a part of everyday work in each team. While for instance rare or major events can play an important role in learning (Christianson et al., 2009; Edmondson et al., 2001), we focus instead on learning integrated in ordinary exchanges among team members doing their everyday work. This suggests that team learning behaviour should be viewed as a characteristic of the team and not merely as an incident.

Performance and task mastery are wanted outcomes of learning, but these outcomes are determined by a number of factors in addition to learning. By measuring processes rather than outcomes we accordingly rule out more intervening or third-variables. In fact, Wilson et al. (2007) assert that the research literature frequently makes no clear distinction between learning and performance. Research on learning should thus allow for a definition of learning as involving a change in the repertoire of potential behaviour (Lähteenmäki et al., 2001). For instance, Sarin and McDermott (2003) proposed a two-step model where they measured assumed determinants of learning, the intermediate team learning process, and team performance (in terms of innovation and time to market). Their results support the assumption that the specified team learning process does contribute to the relevant performance outcomes.

Although a clear consensus about an appropriate definition of team learning has not emerged, the basic premise for a notion of team learning is that it is a property of the team exerting influence beyond the individual driving the process (Wilson et al., 2007). In other words, for an instance of learning to constitute team learning, what the individual has learned must be shared among team members and integrated in their collective understanding (Crossan et al., 1999). We further assume that learning may take place without an instant change in work behaviour or team effectiveness, and we consequently focus on the actual learning processes that may in the long term give rise to increased performance (Chan et al., 2003).

\section{Hypotheses}

We propose that managers in general and team leaders in particular play an important role in facilitating organizational learning in general and team learning in particular. While the literature on team effectiveness has downplayed the role of team leaders, team leader behaviour emerges as a key variable in research on team learning (Edmondson et al., 2007). Previous research has noted the role leaders play in creating an atmosphere where people feel comfortable sharing knowledge, admitting mistakes and openly discussing errors and concerns without fear of being punished (Edmondson, 2003b; Edmondson et al., 2001). Edmondson (2003a) further argues that leaders in particular influence team members' framing of knowledge and experience in relation to tasks and practices. Judge et al. (2004) conclude their meta-analysis by a call for a renewal of interest in the basic leadership behaviour 
dimensions consideration and initiation of structure. We extend this line of research by analysing the possible direct effects on team learning processes, and seek to analyze leader behaviour that encourage or facilitate team learning processes.

While transformational leadership is currently the dominant conception of leader behaviour, consideration and initiation of structure remain relevant tools to characterize leader behaviour as well as robust predictors of key outcomes (Judge et al., 2004; Yukl, 1999a). Empirical evidence also suggests substantial measurement overlap between these classical dimensions and transformational leadership (Seltzer and Bass, 1990; Tracey and Hinkin, 1998). Moreover, previous research indicates that these traditional dimensions impact groups whereas some transformational aspects of leadership primarily impact individuals (Seltzer and Bass, 1990). In the same vein, Yukl (1999b) argued that research on transformational leadership has an overemphasis on dyadic process while group or organizational processes are relatively neglected. This suggests that initiation of structure and consideration are particularly relevant in the context of teams and team learning.

We assume that initiation of structure and consideration can both be displayed in relation to the same group of subordinates. In this regard, Judge et al. (2004) found that consideration and initiation of structure on average had a weak, positive correlation, suggesting that they are not necessarily contradictory aspects of leadership. They also found that consideration and initiation of structure were both positively related to satisfaction, motivation and performance, whereas consideration was more strongly related to satisfaction and motivation. Keller (2006) found that initiation of structure accounted for a unique proportion of variance across several performance measures in research and development teams. Keller specifically noted that initiation of structure predicted higher quality primarily with regard to development projects as compared to research projects. Lloréns-Montes et al. (2005) on the other hand found that supportive leadership promoted learning at the organizational learning as well as innovation. While Sarin and McDermott's (2003) results did not offer support for their hypothesis about consideration, both participation (democratic leadership) and initiation of goal structure positively affected team learning.

Initiation of structure refers to the degree to which the leader structures and defines the leadership role and the role of subordinates concerning job-related activities, such as communicating expectations and assigning tasks. Managers' initiative to define roles, outline requirements and communicate accountability can thus inducing goal directed team learning (Edmondson, 2003a, b). Employees may for instance learn to coordinate activities with other functional areas to ensure that they have adequate input and resources to perform their tasks (Stock and Hoyer, 2002). The work situation of salespeople, such as bank employees, is characterized by their position at the boundary of the company in interaction with customers. A salesperson can accordingly be caught between customers' demands and the company's goals; the structural features imposed by the manager can in this situation be an important guide for the employee even in a relatively structured context such as banking. Leaders that foster a shared understanding and establish a collective mission among members of the team can in turn prompt individuals to share useful information with fellow members. In this regard, initiation of structure also helps to clarify what kind of information is particularly useful, and helps to focus members' attention and energy on relevant areas 
(Locke and Latham, 2002). Similarly, this leadership style may also foster the kind of mindful attention to nuances in the environment that is important for front-line personnel (Weick and Sutcliffe, 2006). Keller (2006) did in indeed find that initiation of structure, by providing the kind of direction lacking in other aspects of leadership, plays an important role in development teams that focus on incremental improvements. This latter contingency is particularly relevant for bank branch offices that operate in a structured environment with a given portfolio of products. In short, initiation of structure contributes to team learning by facilitating communication and encouraging the use of information among team members (Sarin and McDermott, 2003). Based on this reasoning we expect that initiation of structure will contribute positively to team learning:

H1. The more initiation of structure involved in team leadership, the greater the extent of team learning behaviour.

Consideration is the degree to which the leader considers employees' needs, displays concern for their well-being, creates a pleasant atmosphere for interactions, and establishes mutual interests (Stock and Hoyer, 2002). This type of leader promotes a work climate of mutual trust, respect, psychological support, helpfulness and friendliness. Such leaders in particular encourage team members to transcend self-interests for the collective good of the team.

This type of leadership can make employees feel more confident in sharing experiences and newly acquired knowledge as well as proposing ideas, reflecting openly on experiences and admitting mistakes (Edmondson, 2002, 2003b; Sarin and McDermott, 2003; Lloréns-Montes et al., 2005). Leaders may give members the opportunities to voice their opinions and outline suggestions, thus creating a venue for knowledge sharing as well as increasing the motivation to share knowledge by demonstrating its practical relevance. Srivastava et al.'s (2006) finding that empowering leadership positively affected team learning processes in terms of knowledge sharing support this assumption. An illuminating study of a Mt Everest climbing disaster (Kayes, 2004), similarly indicates that reliance on directive (as opposed to supportive or empowering) leadership limited the discretion of individual members and contributed to the breakdown of learning. In short, we expect consideration to facilitate collective learning within the team:

H2. The more consideration is involved in team leadership, the greater the extent of team learning behaviour.

The way tasks are assigned to employees is a characteristic of team management. Whereas conventional wisdom asserts that task performance is maximized by increasing specialization (Hollenbeck et al., 2004), evidence suggests that with regard to team learning close collaboration and multiskilling is more productive (Mittendorff et al., 2006). Similarly, Kira and Frieling (2007) found that individual autonomy was useful for individual learning but not necessarily for collective learning. We accordingly analyze how cross-training (or multiskilling) in particular facilitates collaboration and joint learning in the team.

To achieve the flexibility and joint responsibility typical for teamwork, employees must to some degree be able to perform different tasks within the team, that is, there is 
a degree of multiskilling among team members (Abrams and Berge, 2010). Multiskilling is typically achieved through cross-training of team members. Cross-training in turn means that individual team members are trained on the duties of teammates (Volpe et al., 1996). Cross-training can occur in a variety of ways, such as a highly formal instructional program or as an informal rotation of tasks or positions. Multiskilling or cross-training facilitates team processes such as communication and improves members understanding of the activities of those around them. In this regard, Martínez-Sánchez et al. (2010) found that functional flexibility in a firm was positively related to innovativeness. Team members with an insight into each other's jobs are in a better position to give advice, discuss ideas and understand what information is relevant. Multiskilling and cross-training should therefore be associated with team learning:

H3. The more cross-training in the team, the greater the extent of team learning behaviour.

\section{Method}

Participants and setting

Data for this study comes from branch offices of one Spanish commercial banking corporation. We limited data collection to the Northern regions of Galicia and Asturias. Because most back office services had been centralized and product portfolio at the same time was broadened, branch offices were to a great extent devoted to commercial tasks (such as introducing new products) and customer service. This offered a homogenous setting with regard to tasks, customers and the overall corporate context, while teamwork and leader behaviour (at the discretion of team managers) varies across units or teams. We focus on team learning in terms of an on-going process of knowledge sharing, joint reflection and feedback among members of the team. For a particular team such learning behaviour is a characteristic rather than an event unfolding over a limited period of time. Similarly, leader behaviour is considered an enduring characteristic of a particular manager - at least in the context of a particular team. A snapshot of such typical behaviours can be captured through a cross-sectional design. A quantitative analysis of cross-sectional data relating hypothesized antecedent conditions to extent of team learning behaviour is accordingly warranted.

We mailed questionnaires to 500 branch office employees, and obtained a total of 144 complete questionnaires. Response rates at this level are common for organizational research and in the region of what one can realistically expect (Baruch, 1999), and we did not detect bias that can affect the results. Informants that did not reveal office identity is excluded from further analysis, reducing the available sample of informants to 121 . Among these 23 percent were female. Tenure in the branch office varies from one to 27 years, with a mean at 6.8 and median at four years.

Each of the branch offices we treat as a team in this analysis. At the time of data collection each branch office typically included from a handful to 20 employees (average seven members). We use one or more team members as key informants, that is, our respondents report about properties of the team, rather than about themselves. These reports regard concrete issues that every team member observe or experience, thus avoiding the complex judgements believed to be a threat to the validity of key informant data (Bagozzi et al., 1991; Phillips, 1981). The teams in this study are of 
moderate size, thus supporting our assumption that every team member is adequately knowledgeable about team and leader characteristics. We obtained complete information for variables of interest for a total of 68 teams. For about one quarter of these teams we obtained information from more than one informant, and for these teams we accordingly used the mean score across informants for each variable.

\section{Measures}

Despite the growing interest in teams as a locus of learning in organizations, no widely accepted instrument to measure learning behaviour in teams has yet been established. However, Edmondson's (1999) seminal article developed and validated a survey measurement approach through an exemplary multimethod study. Subsequent studies have built on this measurement approach and have applied Edmondson's (1999) items in other countries and industries. For instance Lantz (Lantz, 2011; Lantz and Brav, 2007) applied the survey instrument in various sectors such as manufacturing, secondary school, homes for the elderly and in a nuclear plant in Sweden. In a study of Australian hospitals, Chan et al. (2003) included items such as "In my group, someone always makes sure that we stop and reflect on our work process". In line with Edmondson's approach our aim was also to measure actual team learning activities in the work context rather than learning outcomes (improvements, knowledge or performance).

To achieve this we designed a questionnaire inviting team members to indicate the degree to which team members engage in specified aspects of joint learning behaviour. Each questionnaire item then captures the degree to which the specified behaviour is typical within that team (see Appendix). Together these items reflect team learning behaviour in a natural context where work and learning is intertwined. Our questionnaire includes statements like "In my branch office, everybody learn from each other in order to improve tasks". Respondents rated statements on a seven-point scale (1 - completely disagree, 7 - completely agree). We formed an index by taking the average of five items intended to measure team learning, the internal consistency (Cronbach's $\alpha$ at 0.91) for these items is satisfactory. This index we use as the dependent variable in the subsequent regression analyses.

We measured the two dimensions of leadership by considering questionnaire items originating from the Ohio State Leadership Studies (see for instance Schriesheim and Kerr, 1974; Tracey and Hinkin, 1998). First, we measured the degree of supervisor consideration as perceived by employees at work. We formed an index from five questionnaire items ( $\alpha$ at 0.90 ) such as "I can rely on my boss when I need him/her". Second, we measured the degree to which the supervisor contributes to initiation of structure in the workplace. Some previous studies have included items measuring leader enforcement of rules and procedures (Schriesheim and Kerr, 1974). For instance Sarin and McDermott (2003) included such items but in their analysis distinguished between "process" and "goal" structure. We intended to measure the degree to which the supervisor defines roles and sets expectations, not the degree to which the supervisor enforces procedures and monitors details. Our measures accordingly largely correspond to Sarin and McDermott's measure of goal structure. We used a total of four items ( $\alpha$ at 0.90 ) including for example "The supervisor compiles concise 
plans with objectives and dates". Principal components analysis (allowing correlation between the factors) sorted items regarding leadership into two distinct factors.

One important aspect of teamworking is the degree to which employees can perform different tasks, that is, multiskilling, and accordingly the degree to which team members engage in cross-training. We measured this variable with items such as "I often work on behalf of an absentee in this office" (Cronbach's $\alpha 0.71$ for two items).

In the analysis we also include the degree of relevant company-specific training as a control variable (Zellmer-Bruhn and Gibson, 2006). This included items such as "I am expected to sell financial products that I'm not trained to sell" (reversed). High score on this variable indicates that employer-provided training is timely and relevant. Table I displays the univariate descriptive statistics and bivariate correlations for all variables.

\section{Results}

We analyzed the relationship between team leadership and teamwork design on the one hand and team learning on the other with linear regression. Table II shows the result of a regression analyses with all hypothesized explanatory variables and one control variable.

The results with regard to leadership show that initiation of structure has a strong relation to learning in branch offices. Supervisor consideration also has some positive influence on learning. Both standardized and unstandardized coefficients are clearly larger for initiation of structure, which indicates that this has the largest effect of the two variables characterising team leadership. The result for these variables supports our hypotheses about the role of leadership in facilitating team learning.

\begin{tabular}{|c|c|c|c|c|c|c|c|c|c|}
\hline & Variable & Mean & $\mathrm{SD}$ & 1 & 2 & 3 & 4 & 5 & \\
\hline 1. & Team learning & 5.01 & 1.44 & 1.00 & & & & & \\
\hline 2. & Consideration & 5.70 & 1.28 & $0.62^{* * *}$ & 1.00 & & & & \\
\hline 3. & Initiation of structure & 5.11 & 1.66 & $0.69 * * *$ & $0.67 * * *$ & 1.00 & & & \\
\hline 4. & Cross-training & 5.69 & 1.56 & $0.33^{* *}$ & 0.12 & -0.03 & 1.00 & & \\
\hline 5. & Training (company specific) & 5.16 & 1.21 & $0.43^{* * *}$ & $0.30^{*}$ & $0.39^{* * *}$ & 0.01 & 1.00 & $\begin{array}{l}\text { Table I. } \\
\text { Means, SD, and }\end{array}$ \\
\hline \multicolumn{9}{|c|}{ Notes: Significant at: ${ }^{*} p<0.05,{ }^{* *} p<0.01$ and ${ }^{* * *} p<0.001 ; n=68$} & correlations \\
\hline
\end{tabular}

\begin{tabular}{lccc}
\hline Independent variables (hypothesis) & $\mathrm{b}^{\mathrm{a}}$ & & $\beta^{\mathrm{b}}$ \\
\hline Initiation of structure $(H 1)$ & 0.43 & $(0.09)^{* * *}$ & 0.50 \\
Consideration $(H 2)$ & 0.23 & $(0.12)^{*}$ & 0.20 \\
Cross-training $(H 3)$ & 0.29 & $(0.07)^{* * *}$ & 0.32 \\
Training (company specific) & 0.20 & $(0.10)^{*}$ & 0.17 \\
$R^{2}$ & & & 0.64
\end{tabular}

Notes: Significant at: ${ }^{*} p<0.05,{ }^{* *} p<0.01$ and ${ }^{* * *} p<0.001$ (significance levels are based on onetailed tests for directional hypotheses, otherwise two-tailed tests); $n=68$; "unstandardized coefficients (standard errors in parentheses); ${ }^{b}$ standardized coefficients

Table II.

Regression analysis with regard to team learning behaviour 
The analysis includes one variable describing training and rotation across tasks in the branch office. The result shows that cross-training has a clear positive influence on team learning. We also included company-specific employee training as a control variable. While training does have some influence on learning in this sample, other coefficients change only marginally when company-specific training is included in the model.

Finally, we note that the $R^{2}$ obtained is substantial indicating that this linear model fits the observations well. One possible reason for the large proportion of variance accounted for is that a homogenous sample and setting leave less scope for random measurement error and unobserved third variables.

\section{Discussion and conclusion}

Many organizations around the world have been changing their structures from a highly hierarchical structure hoping to obtain to a flatter, more responsive, leaner structure. In this context we investigated learning in branch offices of a Spanish commercial bank. Although empirical evidence regarding learning by teams is accumulating, the field is still hampered by lack of a coherent framework. Our results contribute to the understanding of team learning in terms an on-going process of knowledge sharing, joint reflection and feedback among members of the team.

The results presented here support the basic assumption that team leader behaviour plays a key role in facilitating team learning. There is still limited research on the effects of leadership on team learning and we believe our results in this way contribute to knowledge about leadership and collective learning (Bucic et al., 2010; Sarin and McDermott, 2003). Specifically, we compared the effects of initiation of structure and consideration, two correlated yet contrasting aspects of leader behaviour. Both dimensions of leadership are positively related to learning, but our results clearly indicate that initiation of structure has the largest effect. This result corroborates Sarin and McDermott's (2003) finding that initiation of structure rather than consideration contributes to learning. Sarin and McDermott studied product development teams in turbulent high-tech industries; while we studied teams doing relatively structured tasks in the more conservative and highly regulated banking industry. This suggests that conclusions are relatively robust across contexts and in particular that initiation of structure is relevant even in a context that from the outset is relatively structured. Moreover, this comparison of the effects of variables is important, particularly because previous research rarely measures comprehensive sets of variables (Edmondson $e t$ al., 2007). The findings reported here are also consistent with Judge et al's (2004) conclusion that consideration was primarily related satisfaction whereas initiation of structure was related to group performance. Finally, our results are also in line with Keller's (2006) finding that initiation of structure predicted higher quality primarily with regard to development projects as compared to research projects.

Our results do not directly support Edmondson's $(1999,2003 \mathrm{~b})$ classical conclusion that creating psychological safety is key to promoting team learning. Instead we found that creating a clear understanding of roles, accountabilities, goals and collective mission is the kind of leadership behaviour that in particular promotes team learning. Edmondson (1999) did include similar structural features of leader behaviour (clear goal, information, direction setting) in her model of team learning and found positive 
correlations with team learning behaviour. Edmondson did however conclude that the effect of this kind of leader behaviour is mediated by psychological safety. Our empirical findings are largely consistent with Edmondson's (1999), but we differ somewhat in the interpretation of the mediating processes (Sarin and McDermott, 2003). One possible implication is that both leader behaviour in general and goal setting in particular (Locke and Latham, 2002) deserve closer scrutiny in future research on informal learning in natural contexts where work and learning is intertwined.

The results presented are also relevant for the classical distinction between taskand people-oriented leadership. We treat these two basic factors as independent rather than as mutually exclusive dimensions of leadership. Interestingly, our results suggest that task-oriented leadership is more conducive to team learning. One tentative practical implication is that leaders should indeed be task oriented yet maintaining a gentle and caring behaviour. These results contribute to the literature on the virtues of different leadership styles. Further research may uncover possible interactions among coexisting leadership styles.

Leaders setting requirements and goals appear to be most conducive to learning, in addition our results indicate that cross-training or multi-skilling is positively associated with team learning. Our results support conclusions from previous research (Volpe et al., 1996) that cross-training improves team performance; at the same we contribute to research on cross-training by arguing that team learning is one intermediate process. This kind of internal, functional flexibility can also improve organizational innovativeness as well as quality of work life (Martínez-Sánchez et al. 2011). Our findings accordingly present yet another reason for managers to implement functional flexibility through cross-training (see Abrams and Berge, 2010 for a broader discussion). We also found that timely training aimed at specific needs in the workplace is positively related to team learning. This result suggests that team learning may be inspired by training, rather than being a substitute for training. Informal learning as a substitute for formal training means that lack of appropriate knowledge and timely information motivate employees to compensate for the deficiency through informal learning. Instead our results suggest the opposite: work-related training breeds more knowledge sharing and collective reflection. Previous research also included training as a control variable (Zellmer-Bruhn and Gibson, 2006; Edmondson, 1999), and at present we can merely propose explorations into mechanisms connecting training and learning as a topic for further research. Taken together, the results suggest that leaders can beneficially adopt a style characterized by consideration and initiation of structure, and use cross-training to foster team learning.

Our statistical analysis is based on a moderate sample size, thereby limiting the possibility of detecting true relationships. Nonetheless, we gathered data within one homogeneous setting, thus limiting the extent of random measurement error and unobserved sources of variation in the dependent variable (as indicated by a substantial $R^{2}$ ). While having a homogeneous sample and setting is an advantage in the context of statistical analysis, it might limit the ability to generalize specific findings. On the other hand we used an established measurement approach thus facilitating comparisons across studies and contributing to the kind of cumulativ 
research still needed in this field (Wilson et al., 2007). Because we limited our study to team learning as an on-going process, we did not intend to capture the range of phenomena that can be included under the wider umbrella of team learning. The study of other manifestations of team learning, for instance in relation to leadership, remains a challenge for future research (Edmondson et al., 2007). Although most of our survey instruments involve issues not specific to commercial banking or to financial services, the questionnaire is more relevant to services than to manufacturing. Future research could accordingly assess measurements and compare assumed causal relationships across service industries. Future research can also transfer the survey instrument to other national and language settings. Finally, because we mostly use perceptual measures liable to common method bias, future research might explore independent measures of team learning processes.

\section{References}

Abrams, C. and Berge, Z. (2010), "Workforce cross training: a re-emerging trend in tough times", Journal of Workplace Learning, Vol. 22 No. 8, pp. 522-529.

Argote, L. (1993), "Group and organizational learning curves: individual, system and environmental components", British Journal of Social Psychology, Vol. 32 No. 1, pp. 31-51.

Argote, L., Insko, C.A., Yovetich, N. and Romero, A.A. (1995), "Group learning curves: the effects of turnover and task complexity on group performance", Joumal of Applied Social Psychology, Vol. 25 No. 6, pp. 512-529.

Bagozzi, R.P., Yi, Y. and Phillips, L.W. (1991), "Assessing construct validity in organizational research”, Administrative Science Quarterly, Vol. 36 No. 3, pp. 421-458.

Baruch, Y. (1999), "Response rate in academic studies - a comparative analysis", Human Relations, Vol. 52 No. 4, pp. 421-438.

Brown, J.S. and Duguid, P. (1991), "Organizational learning and communities of practice: towards a unified view of working, learning and innovation", Organization Science, Vol. 2 No. 1, pp. $40-57$.

Brown, J.S. and Duguid, P. (1998), "Organizing knowledge”, Callfornia Management Review, Vol. 40 No. 3, pp. 90-111.

Bucic, T., Robinson, L. and Ramburuth, R. (2010), "Effects of leadership style on team learning", Journal of Workplace Learning, Vol. 22 No. 4, pp. 228-248.

Chan, C.C.A. (2003), "Examining the relationship between individual, team and organizational learning in an Australian hospital", Learning in Health and Social Care, Vol. 2 No. 4, pp. 223-235.

Chan, C.C.A., Pearson, C. and Entrekin, L. (2003), "Examining the effects of internal and external team learning on team performance", Team Performance Management, Vol. 9 Nos $7 / 8$, pp. 174-181.

Christianson, M.K., Farkas, M.T., Sutcliffe, K.M. and Weick, K.E. (2009), "Learning through rare events: significant interruptions at the Baltimore \& Ohio Railroad Museum", Organization Science, Vol. 20 No. 5, pp. 846-860.

Crossan, M., Lane, H. and White, R. (1999), "An organizational learning framework: from intuition to institution", Academy of Management Review, Vol. 24 No. 3, pp. 522-538.

Døving, E. (1996), "In the image of man: organizational action, competence and learning", in Grant, D. and Oswick, C. (Eds), Metaphor and Organizations, Sage, London. 
Edmondson, A.C. (1999), "Psychological safety and learning behavior in work teams", Administrative Science Quarterly, Vol. 44 No. 2, pp. 350-383.

Edmondson, A.C. (2002), "The local and variegated nature of learning organizations: a group-level perspective", Orgamization Science, Vol. 13 No. 2, pp. 128-146.

Edmondson, A.C. (2003a), "Framing for learning: lessons in successful technology implementation", Califormia Management Review, Vol. 45 No. 2, pp. 34-54

Edmondson, A.C. (2003b), "Speaking up in the operating room: how team leaders promote learning in the interdisciplinary action teams", Joumal of Management Studies, Vol. 40 No. 6, pp. 1419-1452.

Edmondson, A.C., Bohmer, R.M. and Pisano, G.P. (2001), "Disrupted routines: team learning and new technology implementation in hospitals", Administrative Science Quarterly, Vol. 46 No. 4 , pp. $685-716$.

Edmondson, A.C., Dillon, J.R. and Roloff, K.S. (2007), "Three perspectives on team learning", Academy of Management Annals, Vol. 1 No. 1, pp. 269-314.

Hollenbeck, J.R., DeRue, D.S. and Guzzo, R. (2004), "Bridging the gap between I/O research and HR practice: improving team composition, team training, and team task design", Human Resource Management, Vol. 43 No. 4, pp. 353-366.

Ichniowski, C., Shaw, K. and Prennushi, G. (1997), "The effects of human resource management practices on productivity: a study of steel finishing lines", American Economic Review, Vol. 87 No. 3, pp. 291-313.

Judge, T.A., Piccolo, R.F. and Ilies, R. (2004), “The forgotten ones? The validity of consideration and initiating structure in leadership research", Journal of Applied Psychology, Vol. 89 No. 1 pp. 36-51.

Kayes, D.C. (2004), "The 1996 Mt. Everest climbing disaster: the breakdown of learning in teams”, Human Relations, Vol. 57 No. 10, pp. 1236-1284.

Keller, R.T. (2006), "Transformational leadership, initiating structure, and substitutes for leadership: a longitudinal study of research and development project team performance", Journal of Applied Psychology, Vol. 91 No. 1, pp. 202-210.

Kira, M. and Frieling, E. (2007), "Bureaucratic boundaries for collective learning in industrial work", Joumal of Workplace Learning, Vol. 19 No. 5, pp. 296-310.

Lähteenmäki, S., Toivonen, J. and Mattila, M. (2001), "Critical aspects of organizational learning research and proposals for its measurement", British Joumal of Management, Vol. 12 No. 2 pp. 113-129.

Lantz, A. (2011), "Teamwork on the line can pay off down the line", Journal of Workplace Learning, Vol. 23 No. 2, pp. 75-96.

Lantz, A. and Brav, A. (2007), "Job design for learning in work groups", Joumal of Workplace Learning, Vol. 19 No. 5, pp. 269-285.

Lave, J. and Wenger, E. (1991), Situated Learning: Legitimate Peripheral Participation Cambridge University Press, Cambridge.

Lloréns-Montes, F., Ruiz-Moreno, A. and Garcia-Morales, V. (2005), "Influence of support leadership and teamwork cohesion on organizational learning, innovation and performance: an empirical examination”, Technovation, Vol. 25 No. 10, pp. 1159-1172.

Locke, E.A. and Latham, G.P. (2002), "Building a practically useful theory of goal setting and task motivation: a 35-year Odyssey", American Psychologist, Vol. 57 No. 9, pp. 705-717. 
Martínez-Sánchez, A., Vela-Jiménez, M.-J., Pérez-Pérez, M. and de-Luis-Carnicer, P. (2011), "The dynamics of labour flexibility: relationships between employment type and innovativeness", Joumal of Management Studies, Vol. 48 No. 4, pp. 715-736.

Mittendorff, K., Geijsel, F., Hoeve, A., de Laat, M. and Nieuwenhuis, L. (2006), "Communities of practice as stimulating forces for collective learning", Joumal of Workplace Learning, Vol. 18 No. 5, pp. 298-312.

Phillips, L.W. (1981), “Assessing measurement error in key informant reports: a methodological note on organizational analysis in marketing”, Journal of Marketing Research, Vol. 18 No. 4, pp. 395-415.

Roberts, J. (2006), "Limits to communities of practice", Journal of Management Studies, Vol. 43 No. 3, pp. 623-639.

Sarin, S. and McDermott, D. (2003), "The effect of team leader characteristics on learning, knowledge application, and performance of cross-functional new product development teams", Decision Sciences, Vol. 34 No. 4, pp. 707-739.

Schriesheim, C.A. and Kerr, S. (1974), "Psychometric properties of the Ohio State leadership scales”, Psychological Bulletin, Vol. 81 No. 11, pp. 756-765.

Seltzer, J. and Bass, B.M. (1990), "Transformational leadership: beyond initiation and consideration", Joumal of Management, Vol. 16 No. 4, pp. 693-703.

Srivastava, A., Bartol, K.M. and Locke, E.A. (2006), "Empowering leadership in management teams: effects on knowledge sharing, efficacy, and performance", Academy of Management Joumal, Vol. 49 No. 6, pp. 1239-1251.

Stock, R.M. and Hoyer, W.D. (2002), "Leadership style as driver of salespeoples' customer orientation", Joumal of Market-Focused Management, Vol. 5 No. 4, pp. 355-376.

Tracey, J.B. and Hinkin, T.R. (1998), "Transformational leadership or effective managerial practices?", Group \& Organization Management, Vol. 23 No. 3, pp. 220-236.

Volpe, C.E., Cannon-Bowers, J.A., Salas, E. and Spector, P.E. (1996), “The impact of cross-training on team functioning: an empirical investigation”, Human Factors, Vol. 38 No. 1, pp. 87-100.

Weick, K.E. and Sutcliffe, K.M. (2006), "Mindfulness and the quality of organizational attention", Organization Science, Vol. 17 No. 4, pp. 514-524.

Wilson, J.M., Goodman, P.S. and Cronin, M.A. (2007), "Group learning”, Academy of Management Review, Vol. 32 No. 4, pp. 1041-1059.

Yelle, L.E. (1979), "The learning curve: historical review and comprehensive survey", Decision Science, Vol. 10 No. 2, pp. 302-328.

Yukl, G. (1999a), "An evaluative essay on current conceptions of effective leadership", European Journal of Work and Organizational Psychology, Vol. 8 No. 1, pp. 33-48.

Yukl, G. (1999b), “An evaluation of conceptual weaknesses in transformational and charismatic leadership theories", Leadership Quarterly, Vol. 10 No. 2, pp. 285-305.

Zellmer-Bruhn, M. and Gibson, C. (2006), "Multinational organizational context: implications for team learning and performance", Academy of Management Journal, Vol. 49 No. 3, pp. 501-518. 


\section{Appendix. Questionnaire items (translated from Spanish)}

Team learning behaviour

- When an employee takes part in a course and he/she communicates to colleagues the most interesting application.

- We try to think about the situation in our office team in order to improve our work.

- In my office we share experiences concerning customer complaints and financial services.

- In my office we generate ideas that are transferred to other branch offices.

- In my branch office, everybody tries to learn from each other in order to perform tasks better.

Initiation of structure (office manager behaviour)

- The manager compiles concise plans with objectives and dates.

- The manager is a good example for me in the development of my job.

- The manager gives thoughtful and consistent answers.

- The manager knows how to assert his/her authority when needed

\section{Consideration (office manager behaviour)}

- It is unlikely that my boss gives me bad advice.

- It is easy to talk with my boss about work-related problems.

- My boss encourages me to improve my work methods.

- My boss quickly acknowledges it when an employee does a good job.

- I can rely on my boss when I need him/her.

\section{Cross-training}

- I often work fill in for an absentee at the office.

- I do different jobs. 